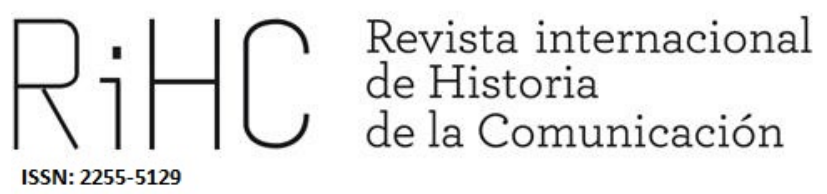

\title{
LA COBERTURA INFORMATIVA \\ DE EL PAÍS SOBRE LA RED \\ SOCIAL FACEBOOK EN 2018
}

The El País information coverage of the social network Facebook in 2018

DOI: http://dx.doi.org/10.12795/RiHC.2019.i13.05

Recibido: 18/10/2019

Aceptado: $11 / 12 / 2019$

Publicado:15/12/2019

Sara Fuentes Garzón

ORCID (D) 0000-0002-6453-0284

Universidad Complutense de Madrid, España

sfuent01@ucm.es 
Resumen: En la adaptación de los medios de comunicación tradicionales a nuevos formatos y soportes digitales el diario español El País ha optado por formar parte de Facebook Journalism Project. Considerando el año 2018, el presente artículo tiene por objeto realizar un análisis cuantitativo y cualitativo de la cobertura informativa llevada a cabo desde la versión digital de El País sobre la red social Facebook. Nos cuestionamos la relación entre ambos espacios digitales, su propósito común por ejercer un periodismo de calidad y qué tipo de información se ha ofrecido finalmente al lector de El País.

Palabras clave: El País, Facebook, redes sociales, Facebook Journalism Project, periodismo digital.

\begin{abstract}
:
In the adaptation from traditional media to new formats and digital media, the Spanish newspaper El País has chosen to be part of the Facebook Journalism Project. Considering the year 2018, the purpose of this article is to carry out a quantitative and qualitative analysis of the information coverage, from the digital version of El País, about the social network Facebook. We question the relation between both digital spaces, their common purpose for exercising a quality digital journalism and what type of information has finally been offered to the reader of El País during the year.
\end{abstract}

Keywords: El País, Facebook, social network, Facebook Journalism Project, digital media.

\title{
1 INTRODUCCIÓN
}

El auge de la comunicación digital ha generado de forma sobresaliente a partir de la primera década del siglo XXI una interdependencia entre la actividad de las redes sociales y la correspondiente al desarrollo de la versión digital de los medios de comunicación tradicionales. A la hora de producir y difundir contenidos informativos en el sistema de comunicación digital se ha constatado que "las redes necesitan contenido y quién mejor que los medios y sus periodistas para llenarlas con sus contenidos profesionales" (Cobo, 2012: 119). La actividad periodística aporta otro tipo de interés y nivel de calidad que el usuario de Internet demanda ante el casi intangible volumen de información al que tiene acceso. Asimismo, considerando los medios de comunicación como parte de esa dinámica comunicativa se determina que "el periodismo digital requiere el dominio de los principios que rigen las redes sociales debido a que es ahí donde se encuentran las audiencias para difundir sus contenidos" (Rosero, 2018: 10). Los medios de comunicación en su versión digital desarrollan múltiples estrategias en relación a la gestión, uso y consumo de sus propios contenidos periodísticos. Sin embargo, en el desarrollo de su actividad precisan la actuación resolutiva de las redes sociales para mejorar la eficacia de su comunicación ante la

\footnotetext{
${ }^{1}$ Una versión previa del texto fue presentada en el XVI Congreso AsHisCom, en Santiago de Compostela.
} 
diversificación tanto del producto periodístico como de su público receptor y emisor de los mismos.

En el periodismo digital se promueve un modelo de comunicación adaptado a Internet $y$, a pesar de ello, resulta necesario considerar siempre que "si Internet ofrece nuevas oportunidades, los medios de comunicación deberían estar pensando en qué pueden ofrecer online para mantener su valor como referente $y$, sobre todo, en cómo cuantificarlo" (Domínguez, 2010: 48). En consecuencia, cuestiones relevantes como la búsqueda de lectores, la innovación en formatos y soportes digitales, la diversificación de la oferta informativa, conllevan una actualización continua sin dejar a un lado el rigor profesional y la exigencia de contar con un acceso fácil y visible. En un ritmo vertiginoso los periodistas realizan su trabajo e interactúan con los usuarios consumidores. $Y$ en esa misma dinámica informativa confluye la actividad de las redes sociales, teniendo en cuenta que "ofrecen a los lectores una variedad de nuevas formas de consumir la información que les importa" (Steffes Hansen, 2015: 165). Como resultado, se constata el progreso de una relación de dependencia recíproca entre los medios de comunicación digitales y las redes sociales donde no sólo son canales de comunicación sino que se comienza a vislumbrar los resultados de sinergias y proyectos innovadores como es el caso de Facebook Journalism Project y, más en concreto, entre Facebook y El País.

El principal objetivo del presente estudio consiste en analizar la cobertura informativa del diario El País en su versión digital durante el 2018 en relación a la red social Facebook. Se trata de un año que conlleva un momento de evaluación de los posibles resultados de la iniciativa Facebook Journalism Project y del cuestionado compromiso por fomentar el progreso de un periodismo digital de calidad. El diario El País declaró su colaboración, como socio en este proyecto empresarial, en enero de 2017 debido a que se pretendía "destacar la información contrastada y veraz" y se aplicaría el desarrollo de formatos innovadores. . Por consiguiente, el estudio realizado comprende un análisis cuantitativo y cualitativo de la cobertura informativa realizada por el diario en su versión digital, es decir, de aquellas informaciones publicadas en la Web de EI País en 2018. La selección de los contenidos en cuanto a su temática consistirá en si se trata de informar sobre los múltiples aspectos de las funcionalidades de Facebook, sobre las novedades de Facebook Journalism Project, si se analiza la participación directa de El País y, también, de cómo se han comunicado las múltiples situaciones polémicas que han erosionado la imagen de la compañía de Zuckerberg en ese mismo periodo de tiempo.

La problemática planteada consiste en poder describir y comprender los argumentos expuestos por El País en 2018 cuando se trata de informar a los lectores sobre Facebook. El principal condicionante es que públicamente se ha explicado que el diario se ha interesado en formar parte de un proyecto periodístico que dirige y gestiona una 
red social, como es Facebook. Asimismo, resulta interesante analizar de qué manera el diario ha podido otorgar una mayor relevancia a la posibilidad de reafirmar la utilidad de esa red social para fines periodísticos y no solo como un canal más de difusión de información. Por otra parte, en ese doble interés por comunicar la actualidad y legitimar la existencia de la red social, consideramos relevante comprobar si durante el 2018 el diario ha tratado de explicar a los lectores las diversas opciones que se presentan a través de Facebook con el fin de valerse de una nueva plataforma digital, de comunicar determinados contenidos y de acercarse a un tipo de lector para transmitir una misma realidad sin olvidar la identidad del medio tradicional.

Teniendo en cuenta la exposición realizada, nos planteamos en primer lugar la hipótesis en relación a la posibilidad de contabilizar el número total de publicaciones empleando únicamente las prestaciones de la página Web de El País. Una segunda cuestión hace referencia a si se puede concluir qué tipo de presentación, análisis y reflexión son propuestas en El País en relación con Facebook y su influencia en la actividad periodística. $\mathrm{Y}$, por último, nos cuestionamos si realmente se comenta a través de la información publicada por el diario el progreso o posible éxito de su participación en Facebook Journalism Project o, si por el contrario, predominan otras temáticas con mayor relevancia o interés para el usuario y que, al mismo tiempo, permitan conocer con mayor precisión la red social Facebook.

En primer lugar, la elección del diario El País dentro de Facebook Journalism Project puede justificarse si consideramos que es una de las principales cabeceras de la prensa española. En 2012 se definía como diario líder de audiencia, con un total de 1.862 .000 lectores. Del mismo modo, era líder en número de seguidores en su perfil de Facebook, con 160.611 usuarios contabilizados en los meses de octubre a diciembre de ese mismo año. Asimismo, en ese periodo de tiempo El País publicó 726 mensajes en la red social y fueron 41.718 veces compartidos (Segado-Boj, Díaz-Campo y Soria, 2015: 156). Como resultado, se puede afirmar que cuenta con un amplio público y ha destacado de forma sobresaliente por su participación e impacto en Facebook. Su posicionamiento como principal diario español de referencia se ha mantenido en estos años y su evolución en el entorno digital hace que sea considerado como un modelo actual de empresa periodística. Según los últimos datos publicados por PRISA Brand Solutions, el diario El País se define como el diario de referencia de España dado que contabiliza en torno a 1,1 millones de lectores diarios y una difusión de 175.065 ejemplares diarios de los cuales el $56 \%$ son ventas en quioscos. Asimismo, es reconocido como líder en generación de contenidos audiovisuales y con una influencia en redes sociales notable donde cuenta con 4,7 millones de seguidores en Facebook ${ }^{2}$.

\footnotetext{
2 Datos obtenidos de la Web de PRISA Brand Solutions. En: https://www.prisabs.com/es/info/el-pais (Última consulta: 10 de diciembre de 2019).
} 
En segundo lugar, hemos presenciado desde el año 2004, momento en el que se fundó la red social Facebook, una evolución de la compañía de Zuckerberg que pretendía responder a las expectativas y exigencias de un mercado global de medios y redes sociales. Un modelo de consumo informativo en el que convergen la interactividad, la inmediatez y el interés que suscitan las redes sociales. $Y$ en ese contexto el usuario de Facebook se inscribe sin plantearse probablemente la razón de "necesitar un sitio de Internet para compartir su vida con las personas que conoce" (Faerman, 2010: 21) cuando decide crear su cuenta. En septiembre de 2006, en Facebook se determinó que toda persona podría convertirse en usuario con la única condición de contar con un mínimo de edad, definido en los 13 años (Delcroix y Martin, 2008: 7). De este modo, la red social se aseguraba aproximarse y comprender todos los perfiles posibles de un gran público joven y también adulto. La principal problemática de ese espacio comunicativo surgía ante la constatación de que "es fácil combinar noticias con comentarios, lo que probablemente sea la razón por la cual el público, cuando es encuestado, dice que desconfía de los medios. La gente confunde fácilmente a los dos" (De Jarnette y Madison, 2018: 120)." La red social había permitido la presencia y participación de los medios de comunicación en su espacio digital. El principal problema consiste en resolver la cuestión fundamental de cómo hacer visible la diferencia entre una información y un comentario y, en definitiva, se trata de afrontar los numerosos casos de desinformación.

A su vez, en ese entorno digital, la multiplicidad de contenidos que se difunden de forma viral hace que los principios fundamentales de la profesión periodística sean cuestionados dado que "si la recomendación social sigue siendo el eje de nuestro consumo digital, los periodistas deben preguntarse qué valor tienen y merecen como prescriptores de la Red" (Noguera, 2012:61). No obstante, como explica el director de Producto de la compañía Facebook, el desarrollo de la red social tiene en cuenta también la resolución de los desafíos actuales y mantienen el propósito de que "a medida que buscamos apoyar el periodismo, también trabajaremos en nuevas formas de ayudar a brindar información a las personas para que puedan tomar decisiones inteligentes sobre las noticias que leen y tener conversaciones significativas sobre lo que les importa" (Simo, 2019: Facebook). El tipo de relación que determinen desarrollar los medios de comunicación con Facebook puede conducir a la confusión por parte de los usuarios si tenemos en cuenta que "mientras el periodismo esté en manos ajenas al propio periodismo no habrá periodismo, habrá información, empresas de servicios y de asesoramiento en comunicación pero ya no se podrá confiar en los medios tradicionales" (Mancinas-Chávez y Reig, 2016: 137). Una de las principales consecuencias más severas implicaría la pérdida de legitimación de los usuarios, lectores antiguos, nuevos o ajenos de la prensa tradicional que promueven la difusión, también digital, de los contenidos periodísticos en sus múltiples formatos y plataformas. 
A principios del año 2017, Facebook decidió impulsar la colaboración con determinados medios de comunicación de referencia internacional, entre los que se encuentran New York Times, The Guardian, BuzzFeed y El País, al implantar Facebook Journalism Project. Con esta iniciativa se logró que a través de Instant Articles se alcanzase "una descarga 10 veces más rápida que los artículos convencionales, un aumento de $20 \%$ en las lecturas de contenidos debido a la velocidad y un $70 \%$ menos de abandono por artículo" (Figueroa y Codina, 2017: 239). En consecuencia, resulta evidente que la empresa de Zuckerberg intenta demostrar que se encuentra en constante evolución. Dispone también de capacidad suficiente para ofrecer resultados positivos a los medios de comunicación. Sin embargo, resulta necesario revisar la idoneidad de su estrategia en tanto que modelo de negocio ante los numerosos casos de desinformación, noticias falsas (fake news) y el uso de datos de usuarios un tanto controvertido.

\section{Cuestión metodológica}

A la hora de definir el objeto de estudio propuesto se ha realizado un análisis cuantitativo y cualitativo sobre la cantidad de contenidos periodísticos publicados desde la versión digital del diario El País y con relación al tipo de información que se ha comunicado en el periodo en cuestión, el año 2018. Para acceder al conjunto de las informaciones publicadas hemos utilizado exclusivamente la herramienta "Buscador", que se encuentra en la propia Web de El País en la parte superior derecha con la imagen de una lupa. Después de varios procesos de selección para determinar la muestra definitiva que conforma el objeto de estudio se ha llevado a cabo un análisis más específico de los contenidos teniendo en cuenta el género periodístico, la temática, la sección correspondiente de la publicación, el tipo de titular y el uso de infografía.

Para analizar el seguimiento informativo llevado a cabo por el diario se han examinado los resultados provenientes de la herramienta "Buscador", dado que sirve para consultar un repositorio de los múltiples contenidos digitales publicados por El País. En esta sección se accede a una presentación de un total de 20 resultados en cada página y los principales parámetros de clasificación disponibles son la "fecha" y el "índice de coincidencia". En un primer momento, nos encontramos con una suma de 43.969 contenidos publicados en la versión digital del diario. Se analizaron el total de 360 resultados considerando un índice de coincidencia superior al 60\%, el alto grado de dispersión de la muestra resultante y teniendo en cuenta las condiciones de uso de la Web de El País. En consecuencia, analizando ese 0,82\% del volumen total de información, el conjunto de la muestra definitiva comprende 82 contenidos 
periodísticos que responden a la temática del objeto de estudio, se corresponde al espacio temporal establecido previamente y se ha logrado al menos precisar un mínimo de informaciones publicadas en cada mes.

\begin{tabular}{|l|l|}
\hline \multicolumn{2}{|c|}{ Parámetros utilizados en la selección de contenidos } \\
\hline $\begin{array}{l}\text { Resultados del } \\
\text { "Buscador" }\end{array}$ & Herramienta de búsqueda en la versión digital de El País \\
\hline Fecha de publicación & Año 2018 \\
\hline $\begin{array}{l}\text { Porcentaje de } \\
\text { coincidencia }\end{array}$ & Más del 60\% establecido por el buscador \\
\hline Temática del estudio & $\begin{array}{l}\text { Facebook Journalism Project ; Facebook ; red social ; } \\
\text { periodismo }\end{array}$ \\
\hline
\end{tabular}

Elaboración propia

El volumen inicial de resultados en la búsqueda implicaría la publicación en la versión digital de El País de una media de 120 informaciones diarias, considerando asimismo ese tipo de periodicidad. Sin embargo, una vez que se identifica el gran número de contenidos periodísticos que no corresponden a los parámetros de selección pero que aparecen entre los resultados de la búsqueda, se ha obtenido un $22,7 \%$ de contenidos que forman la muestra final de informaciones periodísticas relacionadas con el caso de estudio y que podría equivaler al $22,46 \%$ de la publicación anual del diario en su versión digital, si estableciésemos que fuese un asunto tratado diariamente.

En relación a la dispersión de la muestra inicial, hemos constatado que en cuanto a la clasificación por fecha en cada página de resultados se encuentran de dos a cuatro contenidos que no corresponden con la temática del estudio o se han publicado en un periodo de tiempo distinto al indicado. Aparece un mayor número de publicaciones en fechas alternas y sin ningún tipo de orden cronológico a medida que se avanza en el análisis de resultados. La clasificación a partir del "porcentaje de coincidencia" permite la visualización de una presentación jerarquizada, por un orden de mayor a menor coincidencia, pero aparecen intercalados contenidos de temáticas ajenas, una media de uno a tres resultados. En el empleo de ambos parámetros no se dispone de la opción para seleccionar diferentes intervalos, ni ordenar o reducir los mismos, a fin de mejorar la búsqueda. Sin embargo, es preciso tener en cuenta que, como se explica desde El País, esta hemeroteca, configurada a partir del gestor Autonomy, trata de proporcionar al usuario un acceso a la intranet corporativa con el propósito de facilitar la búsqueda concreta de información a través de un lenguaje cotidianoii. Por tanto, presenta un diseño muy visual, detallado y dispuesto para realizar un uso intuitivo y sencillo. 
Cada resultado cuenta con una serie de elementos comunes como la fecha y hora CET de publicación, la representación gráfica del porcentaje de coincidencia, el titular completo, nombre y apellidos del autor o autora, el subtítulo íntegro y una imagen del contenido informativo o del vídeo empleado en la publicación. Asimismo, se presentan los vínculos de "Noticias relacionadas" y "Archivado en" como opciones para llevar a cabo diferentes niveles de lectura y tipos de búsqueda teniendo la posibilidad de llegar a otro espacio informativo donde se accede al perfil de El País en Facebook. El conjunto de estos elementos y comprender el funcionamiento del "Buscador" de El País nos ha permitido identificar y seleccionar correctamente las publicaciones sujeto de estudio.

Para acceder a esa muestra final empleada en la presente investigación se ha considerado el hecho de aceptar, de forma limitada, el uso de datos de navegación para proseguir con una correcta utilización de la página Web del periódico. Es decir, en un primer momento el usuario tiene que aprobar el uso de cookies porque "PRISA utiliza cookies propias y de terceros para mejorar sus servicios, elaborar información estadística y mostrar publicidad, contenidos o servicios personalizados a través del análisis de su navegación" ${ }^{3}$. De este modo, resulta indispensable aceptar estas condiciones de uso para poder consultar los contenidos del medio digital y consintiendo también, entre otros parámetros, la visualización de publicidad de forma continuada. En el caso del estudio realizado y según indica el navegador, se han cedido un total de 120 elementos del historial de navegación y la suma de 226 datos de navegación correspondientes a cookies y otros datos de sitios Web. En consecuencia, se ha optado por imprimir en versión PDF cada uno de los 82 contenidos periodísticos seleccionados para proseguir en el análisis de contenido y tratamiento informativo.

\section{Resultados}

La muestra seleccionada como objeto de estudio comprende el total de meses del año 2018. Se ha conseguido al menos un mínimo de 2 informaciones, como es el caso de los meses de junio y julio, y contamos con un máximo de 13 informaciones en el mes de marzo. La presencia de un mayor número de contenidos publicados a nivel anual se debe a que en los meses de febrero y marzo tuvo lugar el caso de Cambridge Analytica y, en consecuencia, El País realizó un seguimiento más exhaustivo.

\footnotetext{
${ }^{3}$ Nota informativa al inicio del uso de la página Web de El País: https://elpais.com (Última consulta: 10 de diciembre de 2019).
} 


\section{Contenidos analizados de la versión digital de El País publicados en 2018}

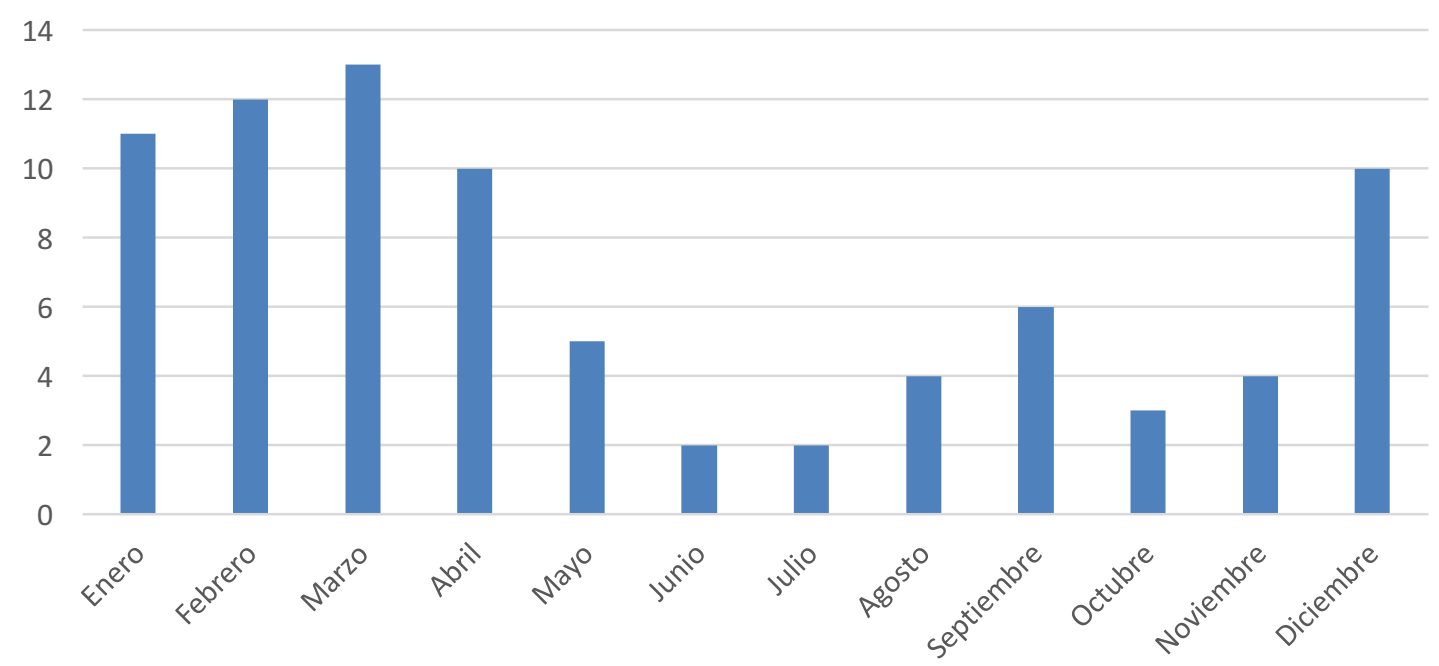

Gráfico de elaboración propia, creado a partir de los resultados obtenidos del "Buscador" de El País.

La sección principal para publicar los contenidos analizados es "Tecnología", seguido de "Internacional" y "Economía". En menor medida se encuentran informaciones en las secciones de "Opinión", "Cultura" y "Ciencia". De forma puntual podemos contar con publicaciones en "Gente" y "Babelia". Por consiguiente, podemos afirmar que la muestra hace referencia a diferentes secciones temáticas propias del diario.

En relación al tipo de géneros periodísticos, contabilizamos tanto contenidos informativos como de opinión. Al analizar el conjunto de contenidos periodísticos, un mayor número corresponde a noticias; seguido de reportajes y en menor medida crónicas. Asimismo, se cuenta de forma puntual con artículos de opinión, como columnas y editoriales. A la hora de analizar los titulares, podemos determinar que suelen ser de una extensión entre siete y doce palabras; de tipo informativo, muy explicativos y empleando un lenguaje sencillo. En todos los contenidos analizados se ha redactado un subtítulo extenso, que puede alcanzar las tres líneas de texto, que completa el sentido del titular y consigue captar la atención del lector por el uso de un lenguaje comprensible y utilizado de forma clara y concisa. Asimismo, el total de los 82 contenidos periodísticos seleccionados presentan elementos infográficos, en la mayoría de los casos son imágenes de gran tamaño y de un gran atractivo visual, que contienen una carga informativa y se sitúan entre el subtítulo y el desarrollo del texto principal.

A lo largo del año 2018, desde el diario El País se incide en tres temáticas principales donde se analiza el valor del usuario, las crisis de reputación y escándalos acontecidos en esos meses y en comprender la ambivalencia de Facebook como espacio 
comunicativo. El periódico apuesta por destacar la importancia de la red social debido a sus capacidades y prestaciones. Sin embargo, no se obvian sus deficiencias y aquellos altercados que han cuestionado la imagen de la empresa de Zuckerberg y su viabilidad en tanto que alternativa para promover el desarrollo de un periodismo de calidad.

\subsection{La preponderancia de la comunidad digital en Facebook para el 2018}

A mediados de enero de 2018 El País publicaba la decisión que había comunicado Mark Zuckerberg, cofundador y presidente ejecutivo de Facebook, por alcanzar el propósito para ese año de impulsar la difusión de los contenidos personales generados por los propios usuarios y reducir los correspondientes de páginas de empresas, marcas y medios de comunicación. Por consiguiente, a través de preguntas directas sobre las experiencias en tanto que miembros de la red social, se consideraba que los usuarios estarían más dispuestos a contar más información sobre sí mismos y podrían también visualizar en primer lugar las publicaciones de familiares y amigos. Tal y como explicaba Zuckerberg, lograr una mejora en la identificación de ese sentimiento de pertenencia a una comunidad permitiría demostrar que en Facebook, que dispone de más de 2.200 millones de usuarios mensuales iii, se valoran principalmente las experiencias de cada uno de ellos. Asimismo, se puede deducir que esta determinación por predominar el valor de los intereses y de las publicaciones de sus usuarios se explicaría por la necesidad fundamental de mantener un alto número de usuarios y en constante incremento porque, mediante su interactividad, son la base de la economía de la red social.

En cuanto a la presencia de los vídeos y contenidos promocionales, el número total de publicaciones disminuiría y su posicionamiento dependería del interés y la confianza que los usuarios hubiesen declarado a través de un sistema de valoración propio de Facebook. En consecuencia, las noticias de los medios de comunicación se redujeron en un $20 \%$ y la veracidad de los medios de comunicación quedó en manos de los usuarios porque, según la red social, se trata únicamente de "medir la confianza que desprenden los medios para dar prioridad a su contenido en la portada de su red social ${ }^{\prime i v}$. Sin tener en cuenta sus audiencias, tendencia política, calidad informativa, nivel de actualidad o el tamaño de la empresa, y con un mayor interés por los medios de comunicación locales, este cambio impactaría en el funcionamiento de las páginas de los mismos en Facebook y en los enlaces que los usuarios decidieran publicar en sus respectivos muros. Una vez más, el incremento de participación de los medios de comunicación y su cercanía al público lector quedaría supeditado por las preferencias personales de los propios usuarios a la hora de favorecer la comunicación y difusión de esos contenidos. 
Una de las primeras reacciones por parte de los medios de comunicación y, asimismo, de los pocos ejemplos que podemos constatar que se haya analizado en El País, corresponde al diario Folha de S. Paulo, considerado el mayor diario de Brasil, líder tanto en su edición impresa como en los medios digitales. El País expuso en una noticia del 9 de febrero de $2018^{v}$ que el periódico brasileño abandonaba Facebook porque, si anteriormente poseía poca relevancia como canal de distribución, ahora supondría una pérdida notable de influencia en la adhesión de lectores para las ediciones digitales. Siendo el primer diario que toma esta decisión, la respuesta de la red social consistió en justificar su medida aludiendo que sólo tienen por objetivo favorecer las relaciones de los usuarios dado que han constatado que se dedica 50 millones de horas diarias menos en los "muros". Si los usuarios publican o redactan menos contenidos en la red social, sean de carácter personal o de otro tipo, es una cuestión que no está sujeta al hecho de promover el interés de los usuarios por compartir contenidos periodísticos, informarse de la actualidad mediante Facebook o generar el hábito de acceder a los medios de comunicación a través de la red social. Y otro aspecto remarcable es la posible sensación de sobreinformación ante una gestión inadecuada de los "muros" al encontrar una gran diversidad de temáticas no siempre afines y una mayor presencia de publicidad. No obstante, resulta evidente que Facebook necesita recuperar y preservar el interés de sus usuarios porque, a menos tiempo de uso de la red, disminuye el volumen de información que generan y que, al mismo tiempo consumen, y ese proceso conlleva pérdidas en el emplazamiento de publicidad y menor cesión de datos entre otras cuestiones.

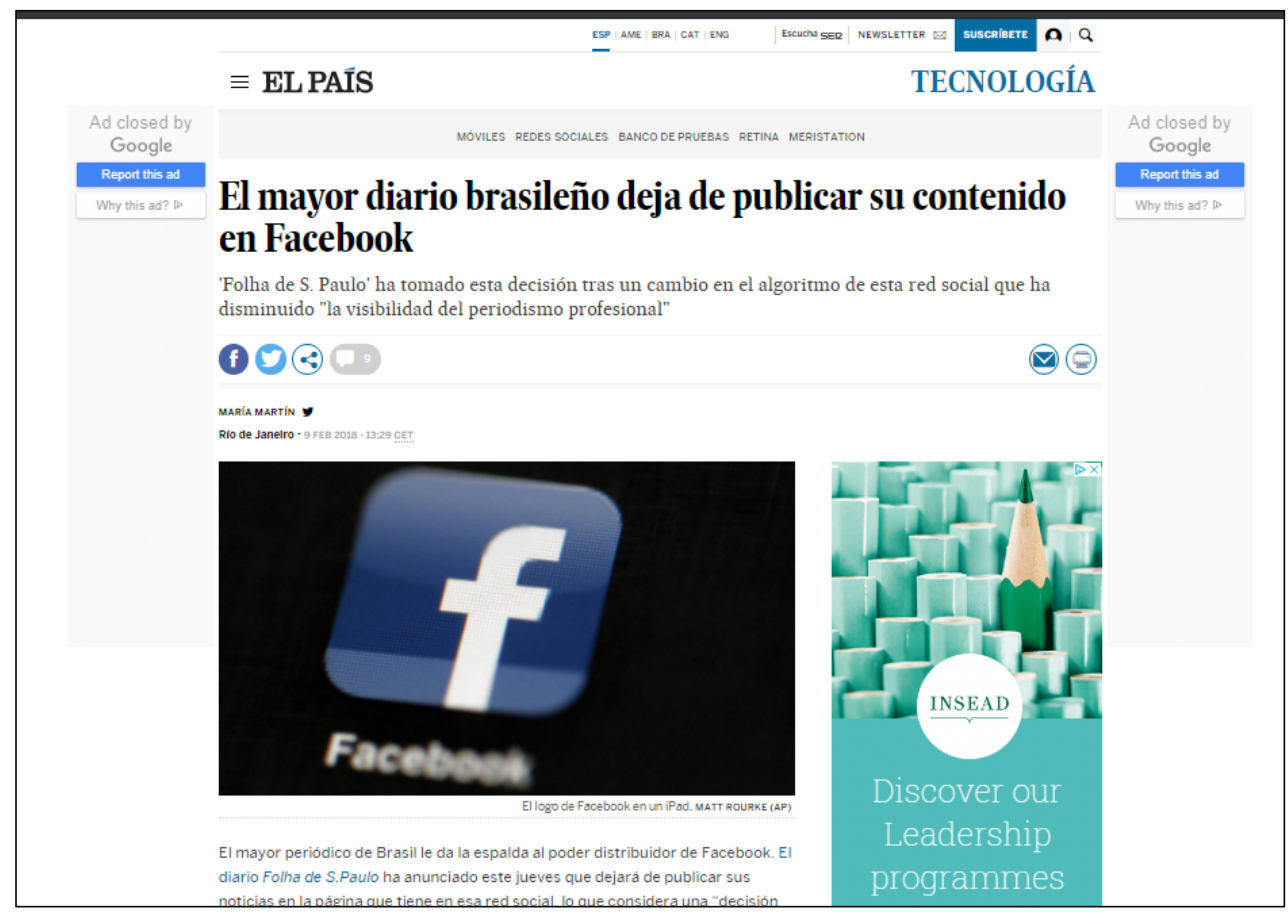

Imagen 1. Noticia de El País, 9 de febrero de 2018. 
La relación con los medios de comunicación no se limita en determinar el posicionamiento, visibilidad y difusión de sus contenidos. Desde el diario El País se informa de cómo Facebook también ha realizado pruebas internacionales sobre la gestión de la información periodística y la utilidad de contar su presencia en su espacio informativo. Más en concreto, el último caso corresponde al 2 de marzo de $2018^{\mathrm{vi}}$ cuando se desestimó el último experimento de la red social debido a la ambigüedad y poca utilidad que expresaron los usuarios. No obstante, desde octubre de 2017, en las cuentas de Facebook de Sri Lanka, Bolivia, Guatemala, Camboya, Serbia y Eslovaquia los usuarios contaron con dos muros diferentes, el habitual de contenidos personales y otro denominado desde la sección "Explorar" para acceder a los enlaces de las noticias de los medios de comunicación. Este es un ejemplo de cómo la red social prosigue en la búsqueda para conciliar la relación con los medios de comunicación aunque la acción más relevante corresponde a Instant Articles, donde se pretende impulsar la suscripción a medios de comunicación a fin de facilitarles ingresos digitales en el espacio Facebook.

\subsection{Red social recomendable a pesar de las diversas crisis de reputación}

La decisión por dar mayor relevancia a los contenidos de los usuarios fue un asunto también cuestionado en El País, mediante reportajes y artículos de opinión, donde se explica abiertamente que el $95 \%$ de la publicidad digital a nivel mundial es controlada por Facebook, Twitter y Google. Ante esta realidad no dudan en afirmar que los anunciantes de publicidad son los verdaderos clientes en ese modelo de negocio a pesar de que se promueva una real comunicación interpersonal. Su estructura empresarial se basa en un sistema informático en el que la atención por analizar las preferencias de los usuarios se combina con los múltiples sucesos de desinformación y esta realidad se justifica teniendo en cuenta que "el algoritmo no distingue verdadero o falso, y nos presenta lo falso como verdadero, porque está diseñado con un objetivo, y solo con un objetivo: maximizar el impacto, la viralidad"vii. Asimismo, existen los recursos técnicos para resolver esta dinámica de difusión de contenidos o incluso dotar de un mayor control de la información a los propios usuarios pero, en tanto que empresas tecnológicas, quedan exentas de esa decisión y de su correspondiente responsabilidad.

En los meses de marzo y abril de 2018 se comunica con mayor frecuencia el conocimiento público de uno de los casos más relevantes en cuanto a la utilización que lleva a cabo Facebook de los datos de usuarios. La consultora Cambridge Analytica habría empleado los datos de unos 87 millones de usuarios de la red social para establecer perfiles psicológicos de posibles votantes aplicándolos posteriormente en la 
campaña electoral de Donald Trump en 2016. Como consecuencia, Facebook afronta una de las mayores crisis hasta el momento en su sistema de negocio publicitario. No sólo son frecuentes las investigaciones y sanciones impuestas por la Comisión Europea desde 2016, sino también se llegan a conocer las acciones emprendidas por cada país tras el suceso Cambridge Analytica. En el mes de octubre, Reino Unido multó a Facebook con la suma de 500.000 libras (565.000 euros) y la Autoridad de Competencia y Garantía del Mercado (ACGM) de Italia impuso en diciembre dos multas de un total de 10 millones de euros viii, lo que supone la más alta sanción europea recibida hasta el momento. La empresa tecnológica de Zuckerberg no queda exenta ante el no respeto al Código del Consumidor mediante la venta de datos de usuarios y, asimismo, precisan que debería resolverse la falta de claridad a la hora de informar al usuario de Facebook en el momento de su registro de que todos los datos que faciliten conllevarán ganancias a nivel comercial aunque se trate de un servicio gratuito en tanto que red social.

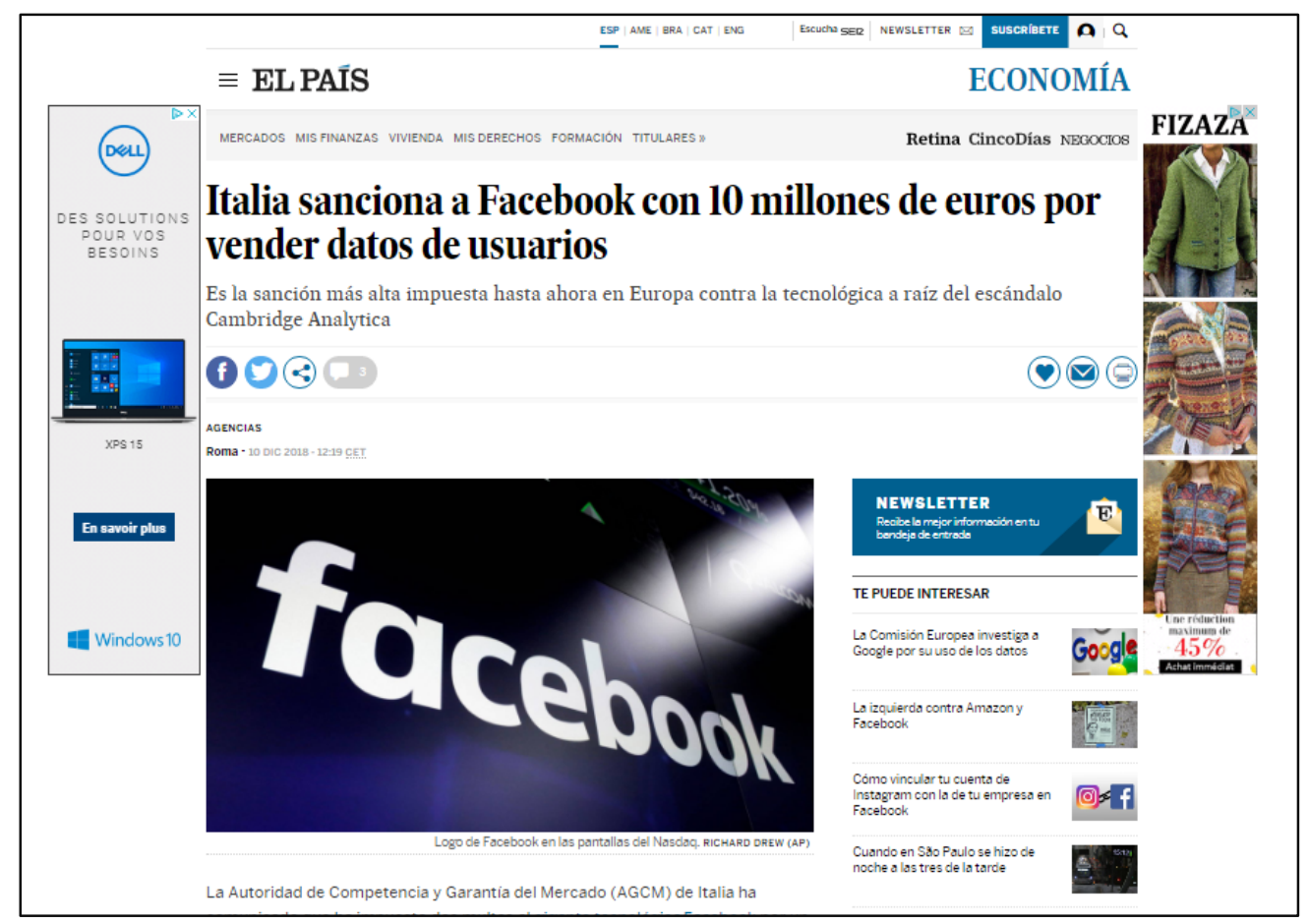

Imagen 2. Noticia de El País, 10 de diciembre de 2018.

La empresa de Zuckerberg tiene que resolver también la falta de credibilidad generada desde que se identificaron más de 260 millones de cuentas duplicadas y falsas, lo que supone un $10 \%$ del total, y que la posibilidad de comprar 1000 "Me gusta" cuesta

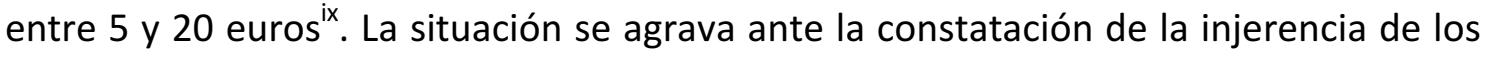
medios rusos por difundir contenidos falsos y generar mayor desinformación. Y en esa circulación constante de contenidos, se ha demostrado que el negocio publicitario de la red social, fundamentado en los intereses de los usuarios, favorece la difusión de "mensajes extremos o los intensamente emotivos que crean discordia, lo cual, a su vez, puede alimentar las "ciberburbujas" de grupos que reflejan y refuerzan 
mutuamente sus opiniones, contribuyendo a impulsar la difusión de contenidos más extremos y facilitando un nicho a los bulos"”. Facilitar la comprensión de las dinámicas comunicativas de Facebook completa el seguimiento informativo sobre su actividad que resulta habitual en El País, puesto que también informa de los fallos de seguridad de la red social. En el mes de diciembre se comunicó un "hackeo" de datos de 29 millones de usuarios a mediados de septiembre y durante doce días 1.500 aplicaciones también pudieron acceder a las fotos de 6,8 millones de usuarios, ya fuesen fotos públicas, del "Stories" o aquellas subidas pero no compartidas ${ }^{\mathrm{xi}}$. La falta de privacidad, incluso debido a errores o ataques al sistema informático, resulta otro de los elementos clave a sobreponer en esa crisis que ya en España ha supuesto pérdidas de 1 millón de euros ${ }^{\mathrm{xii}}$.

\subsection{Un gran espacio de contenidos que depende de la participación de los usuarios}

La posibilidad de mantener e incrementar el número de usuarios en Facebook no resulta una cuestión compleja para la empresa de Zuckerberg a pesar de tratarse de un año complicado. En octubre de 2018 se contabilizaron 2.200 millones de cuentas activas en el mundo, lo que significa casi un tercio de la humanidad. Como explicaron desde El País, aunque se encuentre prohibido en Estados como Siria, Irán, Corea del Norte o China, Facebook está presente en más de 200 países y se dirige a encontrar nuevos usuarios en África y en Asia Central. En Europa, Noruega, Suecia y Dinamarca efectúan el mayor acceso a la red social, más del $76 \%$ de la población respectiva es usuario diario. En cuanto a España, el $65 \%$ de la población dispone de cuenta en Facebook. Si consideramos que en el segundo trimestre de 2018 los ingresos medios por usuario procedentes de anuncios alcanzaron los 8,62 euros por cada usuario en Europa, se puede afirmar que en España lograron ganar alrededor de 25 millones de euros $^{\text {xiii }}$. Los resultados de su actividad empresarial muestran que es un modelo sólido y en constante innovación.

El público que decide formar parte de Facebook comprende todos los perfiles posibles teniendo en cuenta que la edad mínima legal para hacerse una cuenta en la red es de 13 años. Aunque resulta menos interesante en los adolescentes, a partir de entre los 18 y los 20 años se incrementa notablemente el número de creación de cuentas de usuario y se trata de nuevos miembros de Facebook de larga duración. La red social también comprende a la tercera edad $y$, en consecuencia, sigue conservando la exclusividad en cuanto al tipo de audiencia que entra en contacto con sus anunciantes. En el diario El País se tiende a explicar los motivos de los beneficios de formar parte de Facebook porque, aunque sea adictivo y fomente la envidia y la depresión, es la red social donde se cuenta con la mayor oferta de herramientas y funciones de 
expresión ${ }^{\text {xiv }}$. Del mismo modo, el diario hace de plataforma para trasladar consejos sobre cómo gestionar la privacidad y cómo realizar un buen uso de la red social al estar conectado. En el Día Internacional de la Protección de Datos Facebook presentó por primera vez sus siete principios de privacidad fundamentales e informó de la incorporación de un servicio de vídeos educativos, disponible en la sección de "Noticias" (News Feed), en cuanto a la administración de la información y la gestión de datos de los usuarios en la plataforma.

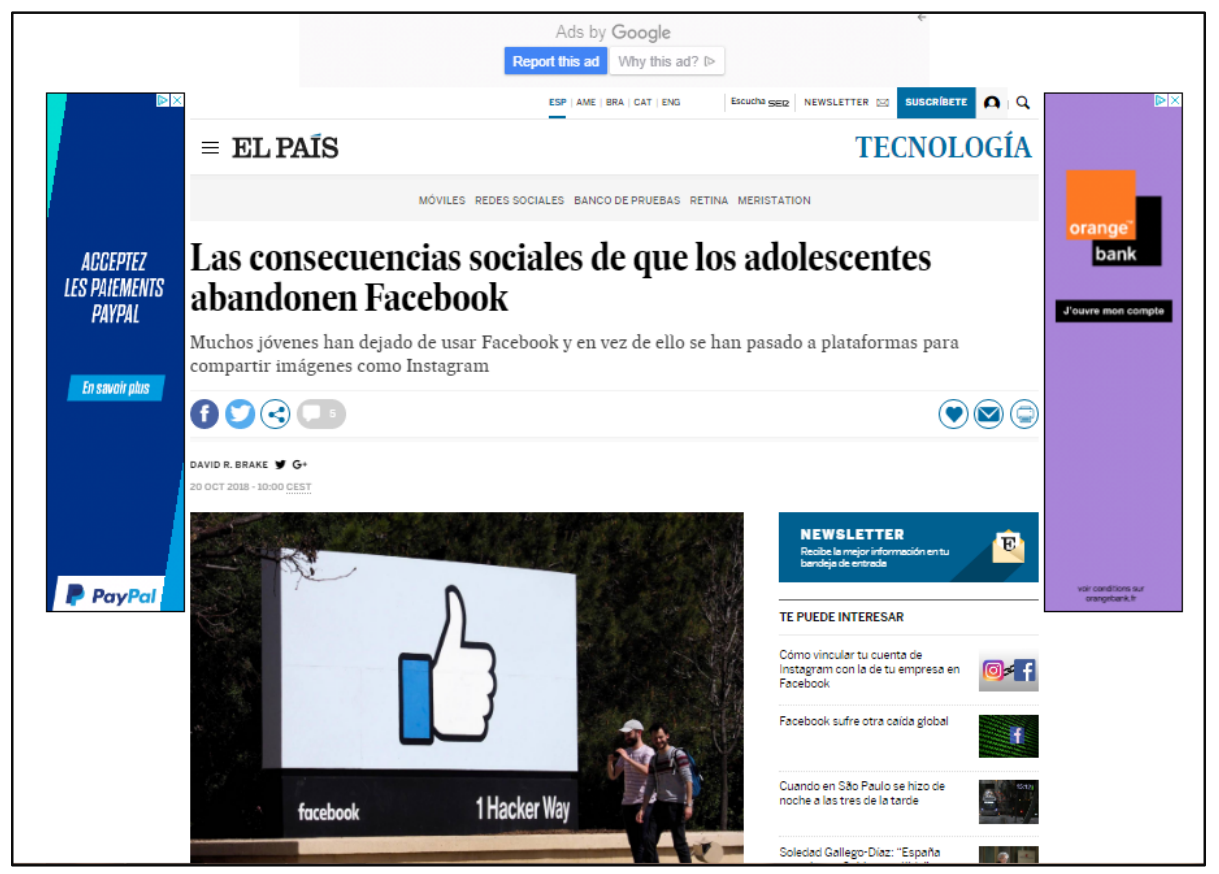

Imagen 3. Noticia de El País, 20 de octubre de 2018

El espacio de comunicación que otorga Facebook llega a albergar múltiples utilidades con fines muy diversos. Como usuario, tan pronto puedes avisar de haber sobrevivido a una catástrofe natural a través de la herramienta "Safety Check" como promover una recogida de fondos benéficos a través de "Facebook Social Good". En el mes de marzo se dio a conocer en el diario las prestaciones de Facebook a fin de promover la proactividad de los usuarios en sus relaciones interpersonales y, asimismo, facilitar las herramientas digitales para generar un mayor impacto social. No obstante, Facebook también ha sido empleada para fines delictivos, como se constata su implicación en tanto que plataforma para la organización de saqueos en el Estado de México en los meses de enero y marzo de 2018 según informó El País. Convertirse en un espacio de incitación y difusión de odio y de violencia también resulta factible. La red social estuvo implicada en los delitos que tuvieron lugar en Myanmar, donde más de la mitad de la población posee una cuenta en Facebook y el $44 \%$ realiza un uso diario, porque se llevó a cabo la difusión de ataques y discursos de odio contra los rohingya y las distintas comunidades religiosas del país ${ }^{\mathrm{xv}}$. La permisible reprobación y control de la información en la red social llega a aplicarse contrariamente en casos que resultan un tanto desacertados, como sucedió en febrero al censurar la publicación de la obra EI 
origen del mundo, pintura de Gustave Courbet, o en marzo la imagen de la Venus de Willendorf.

A la hora de afrontar la cuestión de la desinformación y la circulación de noticias falsas (fake news), la empresa tecnológica también invierte en nuevos proyectos en inteligencia artificial y centros de control de contenidos. En España, tal y como se informa en El País, se instaló a principios del mes de mayo un equipo logístico en la Torre Glòries de Barcelona, muy similar al centro de Essen, para suprimir el contenido perjudicial existente. Recuperar la credibilidad de los usuarios en la red social también se promueve desde la evaluación de la propia confianza que los usuarios generan como resultado de su actividad en Facebook. La red social ha establecido un sistema de valoración del nivel de credibilidad aplicable a los usuarios según las denuncias que reciban y la labor de revisión de contenidos que realizan los técnicos colaboradores de Facebook. En consecuencia, su visibilidad quedaría limitada al predominar una clasificación que privilegia las publicaciones de aquellos usuarios que cuentan con un mayor grado de confianza. Una vez más, la gestión y visibilidad de determinados tipos de contenidos es en gran medida responsabilidad de los usuarios de la red social según sus criterios de preferencia y el buen uso que puedan desarrollar de ese espacio comunicativo. Aunque desde Facebook se esté procurando iniciar un control para garantizar un cierto nivel de calidad y veracidad de la información se trata de una iniciativa que todavía se encuentra en proceso de nuevos resultados y en el que la máxima de Zuckerberg consiste en preservar que la disposición de las publicaciones y los contenidos que se ofrecen determinen a su vez el tipo de consumo informativo.

\section{4 conclusiones}

La participación de El País como socio desde principios de 2017 en el proyecto Facebook Journalism Project podría generar un alto grado de desconfianza hacia el diario y aumentar la controversia sobre el progreso de la red social Facebook. Por tanto, el 2018 ha sido un año clave para comprender el nivel de compromiso de El País a la hora de comunicar a sus lectores consumidores digitales toda aquella información relacionada con Facebook. La cobertura informativa que ha llevado a cabo el diario se puede consultar desde su página Web siguiendo diferentes niveles de lectura y de búsqueda, siempre complementadas a partir de una estructura hipertextual y elementos multimedia. Resulta complicado contabilizar con exactitud el número total de publicaciones en el medio digital, aunque se realice una búsqueda rápida, simple e intuitiva. No obstante, siempre que se acepten las condiciones de uso de la Web, el usuario tiene la posibilidad de dirigir por sí mismo y según sus intereses la propia 
búsqueda. Asimismo, es posible acceder rápidamente a diversos espacios informativos continuando la lectura sobre una misma temática.

El estudio presentado muestra que el periódico El País no ha optado por una comunicación constante y exhaustiva sobre un posible balance de resultados de la participación del propio diario en Facebook Journalism Project, de las innovadoras funcionalidades que van a desarrollar o de las herramientas periodísticas que implementarán. Por el contrario, se analizan las características de la red social, las posibilidades e inconvenientes al definirse como un espacio informativo innovador. $Y$ también se informa sobre las múltiples crisis de reputación y controversias que la empresa de Zuckerberg ha tenido que afrontar durante el año 2018.

Considerando los resultados obtenidos, es posible afirmar que existe un mayor interés por describir la red social como un verdadero espacio donde leer las noticias del diario ordenadas según las preferencias de los usuarios-lectores. En este aspecto, en El País prevalece el discurso sobre impulsar una plataforma de difusión de información y de buena comunicación con los lectores incentivando su responsabilidad y curiosidad. Por tanto, se hace referencia a cuestiones relevantes y de actualidad al comentar de forma argumentada que la gestión de datos también corresponde al propio usuario que genera esa información, que es posible determinar el nivel de privacidad y que se asume una responsabilidad al formar parte de una comunidad digital como Facebook.

El presente estudio nos permite comprender de forma más precisa de qué manera a través de un medio de comunicación es posible conocer también una red social. Considerando esa relación de interdependencia, es posible determinar cómo El País ha informado sobre la red social Facebook en 2018 realizando un seguimiento informativo online completo, diverso y riguroso. A través de diferentes tipos de textos periodísticos publicados han explicado los motivos de cómo Facebook pretende definirse como un espacio comunicativo con múltiples informaciones para todo tipo de públicos. Del mismo modo, se presenta diversas acciones previstas para mejorar las prestaciones de la red social, resolver los problemas de confidencialidad, suprimir contenidos violentos y evitar casos de desinformación. El diario se convierte en un espacio informativo y de reflexión para los lectores al cuestionar cómo Facebook podría mejorar la actividad de los medios de comunicación en el entorno digital y que el usuario continúe decidiendo libremente cómo participar, qué compartir y qué se considera relevante.

A partir del estudio propuesto es posible sugerir otras investigaciones posteriores. Por una parte, sería interesante realizar una comparativa de la cobertura informativa llevada a cabo en el mismo periodo de tiempo por los otros medios de comunicación que también son socios en Facebook Journalism Project. El objetivo principal del estudio sería determinar hasta qué punto o de qué manera un medio de comunicación llegaría a modificar sus contenidos periodísticos ante la influencia de otras sinergias empresariales. Tal vez, no todos los diarios implicados se han interesado por los 
mismos asuntos, relevantes o secundarios, o, probablemente, han comenzado a seguir un mismo proceder a la hora de difundir determinados contenidos periodísticos.

Por otra parte, en relación a la evolución del proyecto, también sería interesante analizar la cobertura informativa realizada a medio o largo plazo por un mismo medio de comunicación considerando su actividad o el tipo de colaboración en Facebook Journalism Project. En este supuesto, sería posible cuestionarse el éxito de esa iniciativa innovadora basada en llevar a cabo un periodismo de calidad adaptado al entorno digital. Habría que plantearse si aquello que entendemos como "periodismo digital de calidad" ha variado al formar parte de un entorno cambiante y ante la intervención de nuevos actores o elementos externos. Por tanto, se podría comparar de qué modo han evolucionado los medios de comunicación implicados en el proyecto, cómo ha sido desarrollado el vínculo de la red social y el medio de comunicación, cómo ha cambiado su actividad periodística digital. Teniendo en cuenta estos tres parámetros, el propósito sería poder establecer un análisis cuantitativo y cualitativo considerando los resultados de un posible progreso y teniendo como referencia los principios fundamentales acordados en los inicios de Facebook Journalism Project.

\section{Referencias bibliográficas y fuentes}

COBO, Silvia (2012): Internet para periodistas: kit de supervivencia para la era digital. Barcelona, España: UOC.

DE JARNETTE, Ben, y MADISON, Ed (2018): Reimagining Journalism in a Post-Truth World: How Late-Night Comedians, Internet Trolls and Savvy Reporters Are Transforming News. California, Estados Unidos: Praeger.

DELCROIX, Éric, y MARTIN, Alban (2008): Facebook: On s'y retrouve. París: Pearson Editions.

DOMÍNGUEZ, Eva (2010, 1a edición): El Cuarto BIT: Una década de reflexiones sobre periodismo e Internet. Barcelona, España: UOC.

FAERMAN, Juan (2010, 1a edición): Faceboom: Facebook, el nuevo fenómeno de masas. Barcelona, España: Alienta.

FIGUEROA ENCINA, Patricio, y CODINA, Lluís (2017): “Nuevos formatos móviles para noticias: El caso de El País y la utilización de los Instant Articles de Facebook", en DE LARA GONZÁLEZ, Alicia y ARIAS ROBLES, Félix (coords.): Mediamorfosis. Perspectivas sobre la innovación en periodismo. Elche, España: Universidad Miguel Hernández de Elche, pp. 230-249. 
MANCINAS-CHÁVEZ, Rosalba y REIG, Ramón (2016): "Poder y ética periodística en la era digital", en CRUZ ÁLVAREZ, Jesús y Suárez Villegas, Juan Carlos (eds.): Desafíos éticos en el periodismo digital. Madrid, España: Dykinson, pp. 133-148.

NOGUERA, José Manuel (2012): Redes y periodismo: cuando las noticias se socializan. Barcelona, España: UOC.

ROSERO VACA, Fabricio (2018, 1a edición) "Periodismo digital y el camino a la democratización de la comunicación", en LARREA, Ana María, MANTILLA, Paola y ROSERO VACA, Fabricio (coords.): Periodismo Digital: Tras las comunidades sostenibles en el ciberespacio. Egregius Ediciones, pp. 9-10.

SEGADO-BOJ, Francisco, DÍAZ-CAMPO, Jesús y SORIA, María (2015) "La viralidad de las noticias en Facebook. Factores determinantes", en DÍAZ-GARRETA, Alejandro (ed.): TELOS 100: La era digital. Balance y tendencias. Febrero-Mayo. Madrid, España: Fundación Telefónica, pp. 152-161.

STEFFES HANSEN, Sara (2015, 2a edición) "Social Media", en FILAK, Vicent F. (ed.): Convergent Journalism: An Introduction. Writing and Producing across Media. Burlington, Estados Unidos: Focal Press. pp. 165-186.

SIMO, Fidji (2019): Introducing the Facebook Journalism Project. Publicado en la Web de Facebook: https://www.facebook.com/journalismproject/introducingfacebook-journalism-project (Última consulta: 10 de diciembre de 2019).

Publicaciones citadas de El País en su versión digital:

'Seco, Raquel. "Facebook apuesta por el periodismo de calidad", sección Tecnología. Publicado el 11 de enero de 2017. En: https://elpais.com/tecnologia/2017/01/11/actualidad/1484145535_207227.html (Última consulta: 10 de diciembre de 2019).

ii Reventós, Laia. "El buscador, puerta de entrada a la intranet corporativa", sección Internet. Publicado el 8 de mayo de 2018. En: https://elpais.com/diario/2008/05/08/ciberpais/1210213467_850215.html (Última consulta: 10 de diciembre de 2019).

iii Torres Menárguez, Ana. "Facebook por dentro: un día en el imperio de Zuckerberg”, sección Tecnología. Publicado el 2 agosto de $2018 . \quad$ En: https://elpais.com/tecnologia/2018/07/30/actualidad/1532948227_667966.html (Última consulta: 10 de diciembre de 2019).

iv Jiménez Cano, Rosa. "Facebook dará más relevancia a los medios veraces", sección Tecnología. Publicado el 20 de enero de 2018. https://elpais.com/tecnologia/2018/01/20/actualidad/1516405376_224940.html (Última consulta: 10 de diciembre de 2019).

"Martín, María. "El mayor diario brasileño deja de publicar su contenido en Facebook", sección Tecnología. Publicado el 9 de febrero de 2018 . En: https://elpais.com/tecnologia/2018/02/09/actualidad/1518170231_523757.html (Última consulta: 10 de diciembre de 2019).

vi Jiménez Cano, Rosa. "Facebook recula y pone fin al experimento de excluir a los medios de los muros de los usuarios", sección Tecnología. Publicado el 2 de marzo de 2018. En: 
https://elpais.com/tecnologia/2018/03/02/actualidad/1519982738_951932.html (Última consulta: 10 de diciembre de 2019).

vii Garicano, Luís. "Bulos en las redes sociales: ¿debemos regular los algoritmos?", sección Economía. Publicado el 21 de enero de 2018 . https://elpais.com/economia/2018/01/19/actualidad/1516353089_781462.html (Última consulta: 10 de diciembre de 2019).

viii Agencias. "Italia sanciona a Facebook con 10 millones de euros por vender datos de usuarios", sección Economía. Publicado el 10 de diciembre de $2018 . \quad$ En: https://elpais.com/economia/2018/12/10/actualidad/1544439119_932684.html (Última consulta: 10 de diciembre de 2019).

ix Peinado, Fernando; Alameda, David. "El mercado global de los "me gusta" falsos", sección Internacional. Publicado el 7 de abril de 2018. En: https://elpais.com/internacional/2018/04/03/actualidad/1522769651_850596.html (Última consulta: 10 de diciembre de 2019).

`Vince, Gaia. "Por qué las buenas personas se vuelven 'trolls' en Internet", sección Tecnología. Publicado el 22 de abril de 2018 . https://elpais.com/tecnologia/2018/04/16/actualidad/1523871306_559376.html (Última consulta: 10 de diciembre de 2019).

${ }^{x i}$ Pérez Colomé, Jordi. "Un fallo de Facebook permite que 1.500 apps accedan a fotos de 6,8 millones de usuarios", sección Tecnología. Publicado el 14 de diciembre de 2018. En: https://elpais.com/tecnologia/2018/12/14/actualidad/1544803995_355729.html (Última consulta: 10 de diciembre de 2019).

xii Sérvulo González, Jesús. "Facebook declara pérdidas en España y los auditores avisan del riesgo de su estrategia tributaria", sección Economía. Publicado el 25 de septiembre de 2018. En: https://elpais.com/economia/2018/09/24/actualidad/1537815104_191690.html (Última consulta: 10 de diciembre de 2019).

xiii Pérez Colomé, Jordi. "Un artículo científico desglosa por primera vez las cifras de Facebook (y son apabullantes)", sección Tecnología. Publicado el 4 de octubre de 2018. En: https://elpais.com/tecnologia/2018/10/03/actualidad/1538596216_048867.html (Última consulta: 10 de diciembre de 2019).

xiv Brake, David R. "Las consecuencias sociales de que los adolescentes abandonen Facebook", sección Tecnología. Publicado el 20 de octubre de $2018 . \quad$ En: https://elpais.com/tecnologia/2018/10/16/actualidad/1539703179_416049.html (Última consulta: 10 de diciembre de 2019).

" Pérez Colomé, Jordi. "Así contribuye Facebook a la violencia, y no tiene una solución fácil”, sección Tecnología. Publicado el 12 de noviembre de 2018. En: https://elpais.com/tecnologia/2018/11/12/actualidad/1541989953_312010.html (Última consulta: 10 de diciembre de 2019). 